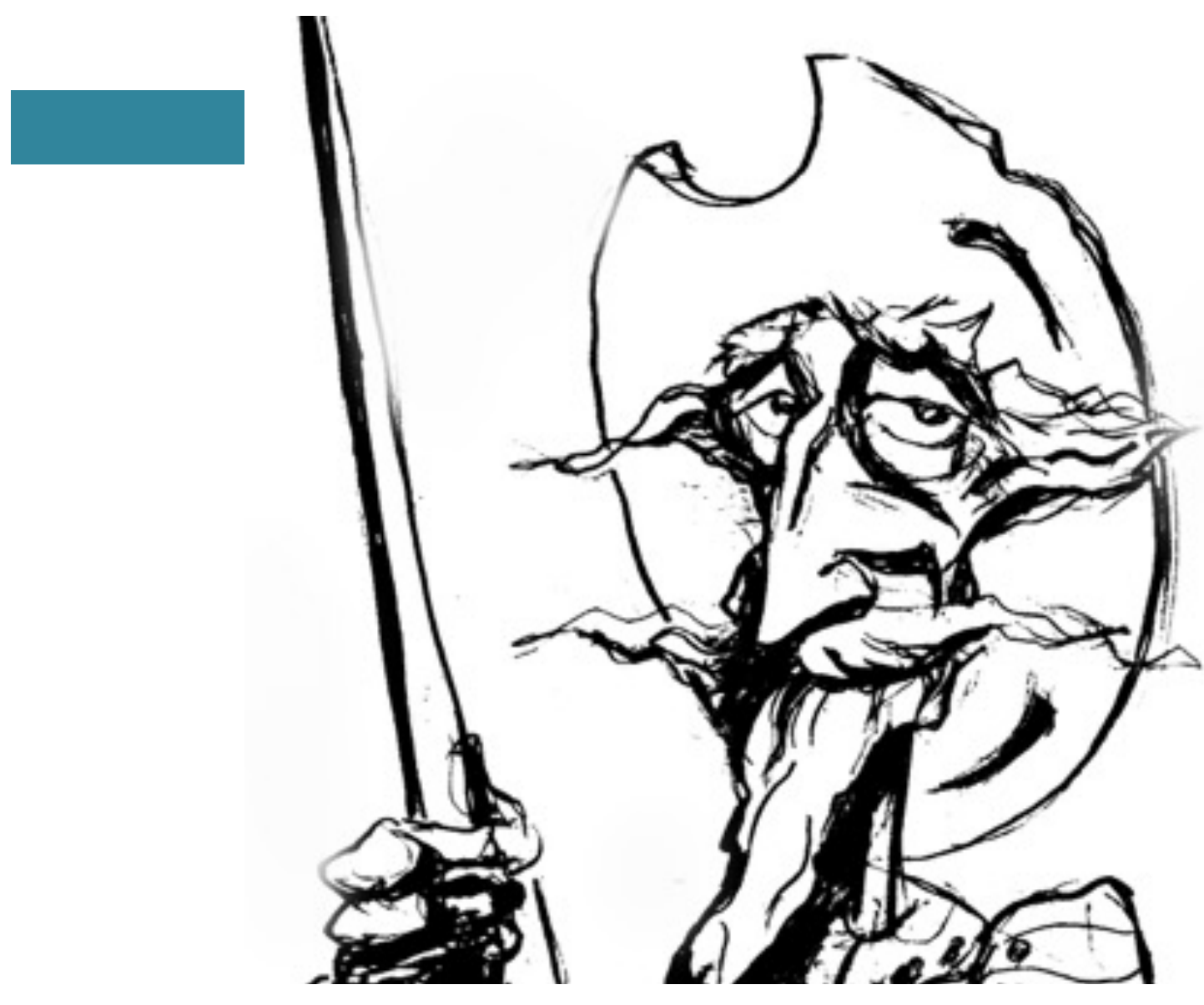

Buenos Aires y la temprana globalización. Pensamiento y praxis de Martín Ignacio de Loyola, 1580-1605

[Mariano Bonialian] 


\title{
Buenos Aires y la temprana globalización. Pensamiento y praxis de Martín Ignacio de Loyola, 1580-1605*
}

\author{
Buenos Aires and the Early Globalization. Thought and Praxis of Martín \\ Ignacio de Loyola, 1580-1605
}

MARIANO BONIALIAN

\begin{abstract}
Resumen
El artículo analiza el pensamiento y la práctica global que tuvo el franciscano Martín Ignacio de Loyola al arribar a la gobernación de Paraguay y Río de La Plata a fines del siglo XVI. Se demuestra la gravitación que alcanzó el pensamiento y la actuación de Loyola en el desarrollo de la economía, de la sociedad y de la política por la Gobernación a partir de su experiencia global previa en China realizando la actividad misionera. En las últimas páginas de trabajo, se presenta una desconocida ilustración sobre la citada gobernación en el contexto global. Se explora la posible autoría de Loyola, dada la similitud de problemáticas que los une.
\end{abstract}

\section{Palabras clave}

Globalización - Gobernación del Paraguay y Río de La Plata - Martín Ignacio de Loyola - China - Monarquía Hispánica

\begin{abstract}
The essay analyzes the thought and global practice that the Franciscan Martín Ignacio de Loyola had when he arrived in the governorate of Paraguay and Rio de La Plata Aires at the end of the 16th century. It demonstrates the gravitation that Loyola's thought and action reached in the development of the economy, society and politics by the Governorate, based on his previous global experience in China carrying out missionary activity. In the last pages of the work, an unknown illustration is presented on the mentioned governorate in the global context. The possible authorship of Loyola is explored, given the similarity of the problems that unite them
\end{abstract}

\section{Key words}

Globalization - Paraguay and Río de La Plata governance - Martín Ignacio de Loyola - China Hispanic Monarchy

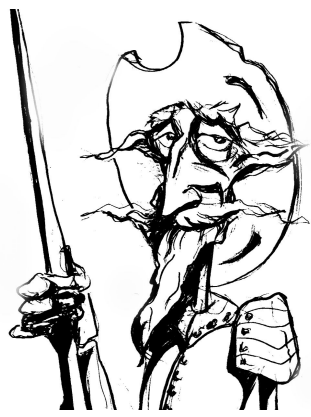

Recibido con pedido de publicación el 30 de julio de 2018

Aceptado para su publicación el 14 de octubre de 2018

Versión definitiva recibida el 2 de diciembre de 2018

Mariano Bonialian, Centro de Estudios Históricos, El Colegio de México, México; e-mail: marianobonialian@gmail.com

* Agradezco las recomendaciones recibidas por parte de los evaluadores anónimos.

Esta obra se publica bajo licencia Creative Commons. Atribución-NoComercial-CompartirIgual $(\mathrm{cc})$ EY-NC-sA 4.0 Internacional

Bonialian, Mariano "Buenos Aires y la temprana globalización. Pensamiento y praxis de Martín Ignacio de Loyola, 1580-1605”, Prohistoria, Año XXI, núm. 30, dic. 2018, pp. 3-31. 
Con intenciones de superar los rígidos paradigmas de la historia nacional, los especialistas de la historia mundial o World History discuten el punto inaugural del pasado global. ¿Cuándo se inicia la globalización? ¿A principios del siglo XIX, con la creación de un mercado único de precios? ¿Es un fenómeno más temprano, con el comercio y las navegaciones marítimas de larga distancia uniendo sociedades y culturas distantes? Con cierto sesgo economista y etnocentrista, los defensores de la primera posición enfatizan la convergencia de precios en un mercado global a partir de los efectos generados por la revolución industrial inglesa y el expansionismo del capitalismo europeo sobre espacios que hasta entonces no había dominado. Los historiadores que defienden una temprana globalización cuestionan la mirada teleológica de la historia de la primera interpretación. Sugieren que las tempranas conexiones transoceánicas movilizando bienes, flora y fauna, ideas y personas constituye el origen mismo de la globalización. La navegación transpacífica inaugurada con el galeón de Manila (1565) se convierte en la última pieza faltante para configurar el primer tablero mundial en la historia. ${ }^{1}$

En efecto, el avance de la mundialización ibérica desde el siglo XVI constituye el disparador esencial para la temprana globalización. ${ }^{2}$ Es cierto que el reino de Portugal tomó la iniciativa, materializado en la carrera hacia las especies asiáticas por la ruta del Cabo de Buena Esperanza. Pero el avance español por su lado oeste posibilitó que la América española sea un actor principal en el tejido global. El galeón de Manila es la manifestación decisiva de esa proyección hacia China, posicionando a México como el centro monárquico para la interacción planetaria. Gran parte de la movilidad de objetos y personas que vemos fluir dentro del campo monárquico forman parte y dan sentido a las interacciones globales. Los circuitos trasatlánticos y transpacíficos conectando a la América española con Europa y China muestran unos límites monárquicos permeables a lo externo. El carácter poroso de las fronteras monárquicas remite a su función de puentes comunicantes para la interacción y extendida red de saberes, cultura material y personas. ${ }^{3}$

\footnotetext{
${ }^{1}$ FLYNN, Dennis y GIRÁLDEZ, Arturo "Los orígenes de la globalización en el siglo XVI", en HAUSBERGER, Bernd e IBARRA, Antonio (coords.) Oro y plata en los inicios de la economía global: de las minas a la moneda, El Colegio de México, México, 2014, pp. 29-76.

${ }^{2}$ GRUZINSKI, Serge Las cuatro partes del mundo. Historia de una mundialización, Fondo de Cultura Económica, México, 2010.

${ }^{3}$ La relación entre Monarquía hispana y globalización es un tema de interés reciente en la historiografía. Para un primer acercamiento, véase: HAUSBERGER, Bernd Historia mínima de la globalización temprana, Centro de Estudios Históricos, El Colegio de México, 2017; BONIALIAN, Mariano China en la América Colonial. Bienes, mercados, comercio y cultura del consumo desde México hasta Buenos Aires, Biblos-Instituto Mora, Argentina-México, 2014; ARAM, Behany y YUNCASALILLA, Bartolomé (eds.) Global Goods and the Spanish Empire, 1492-1824. Circulation, Resistance and Diversity, Palgrave Macmillan, London, 2014.
} 
La experiencia vivida por el religioso Martín Ignacio de Loyola es un caso representativo de la circulación de pensamientos y acción a escala global. El franciscano le dedica 25 años de un poco más de sus 50 años de vida a emprender dos viajes completos por el mundo y dos travesías trasatlánticas entre Europa y Sudamérica. Loyola es un hombre global, una de las personalidades más viajada en esos tiempos, un verdadero trotamundos. La pluma de Serge Gruzinski lo coloca dentro del grupo de las "elites católicas mundializadas". ${ }^{4}$ En 25 años transita y conoce Asia, África, la América española y Europa, realiza planes de conversión religiosa y socioeconómicas con gran aliento transformador, logra un dominio de lenguas no europeas, amerindias y asiáticas y cada espacio que visita o reside lo comprende superando fronteras regionales e imperiales.

Loyola nace a mediados del siglo XVI (¿1550?) en la España vasca de Éibar y muere en Buenos Aires hacia 1606. Su estilo de vida nómada lo hereda, en parte, de su línea paterna familiar: los Mallea. Su padre, Andrés de Mallea, emprende negocios mercantiles entre Europa y Gran Bretaña, operando más tarde en el comercio de las flotas de Portobelo, hasta convertirse en un rico encomendero por su participación en la hueste conquistadora de Nueva Granada. ${ }^{5}$ Sin embargo, su reconocimiento vendrá de su familia materna: es nada menos que el sobrino nieto de San Ignacio de Loyola, fundador de la Compañía de Jesús. Seguirá los pasos de vida religiosa como su tío, pero bajo la orden franciscana. En 1582 alcanza el nombramiento de primer custodio de la provincia franciscana de Macao-Malaca. En 1595, luego de sus dos viajes planetarios y con desafortunados resultados en China, su tío, el duque de Lerma, muy cercano a Felipe III, le conseguirá una nueva misión religiosa en la Gobernación de Paraguay y Río de La Plata. Fruto de su misión lo nombran en 1603 como cuarto obispo de Paraguay y Río de La Plata.

En China, Loyola se esmera en el plan de evangelización sobre la resistente sociedad China. Necesita legitimidad: encuentra el apoyo en las máximas autoridades políticas, codeándose con los reyes católicos y con el Papa. Vive en conflictos permanentes con los portugueses al emprender su misión asiática, pero años después, instalado en Buenos Aires, los defiende ante la expulsión decretada por la Monárquica. Es un defensor de los intereses reales, pero cuestiona a México, Panamá y a Lima en calidad de bastiones que garantizan la defensa de las Indias Occidentales. Valoriza las "periferias" del imperio, como las islas Filipinas y Buenos Aires, hasta el punto de defender la libertad de comercio del puerto austral con el Brasil y África. Se convierte en el

\footnotetext{
${ }^{4}$ GRUZINSKI, Serge Las cuatro partes..., cit., pp. 280-288.

${ }^{5}$ MOLINA, Raúl Fray Martín Ignacio de Loyola. Cuarto Obispo de Paraguay y Río de la Plata (16031606), Jura, Madrid, 1953, pp. 7-8. Tíos y primos de Martín Ignacio también se movilizan entre Europa y América. TELLECHEA IDÍGORAS, Ignacio Martín Ignacio de Loyola. Viaje alrededor del mundo, Historia 16, Madrid, 1989, pp. 12-14.
} 
principal aliado del gobernador de Buenos Aires Hernando Arias de Saavedra, más conocido como Hernandarias. Sus compromisos políticos no le impiden formar parte del pequeño grupo de franciscanos que inician el sistema de reducciones sobre los pueblos indígenas de la región de Asunción, Paraguay.

Dos elementos consagran a Loyola como pensador global: el ejercicio comparativo y ser testigo ocular de los hechos. Lo que observa en Europa, en Oriente y en América hispana pasa inevitablemente por el cotejo. México es definida como una de las ciudades "de las buenas del mundo [...] fundada en el agua al modo y manera de Venecia en Italia [...] un reino que se compara a cualquiera de los mayores y más ricos de todos lo que se saben en el mundo, fuera del de la China". ${ }^{6}$ Macao la define como un gran puerto porque cuenta "con más navíos que en toda la costa de España". Recurrirá a la Corona por mayores recursos destinados a Buenos Aires porque su privilegiada posición geoestratégica es tan importante como la que presenta, para el caso de América septentrional, La Habana. En definitiva, lo que Loyola experimenta en China, en sus viajes transpacíficos, trasatlánticos o en su recorrido por la América española lo decanta en sus reflexiones sobre el espacio donde vive sus últimos años de vida: la Gobernación de Asunción y Río de La Plata. La evolución de Loyola es la clara manifestación del juego dialéctico entre praxis y pensamiento en grados de escalas espaciales que transitan entre lo global y lo local.

El escrito contiene tres apartados. El primero de ellos se ocupa sobre sus experiencias en tierras asiáticas y travesías globales. Posteriormente, se analiza la gravitación que alcanza el pensamiento y la actuación de Loyola para el desarrollo de la economía, la sociedad y la política en la Gobernación de Paraguay y Río de La Plata. Las ideas y reformas que busca aplicar sobre el puerto y la región austral se explican por sus anteriores viajes circunnavegando el mundo y China. En el tercer apartado, se presenta y analiza un inédito boceto de la dicha gobernación que realizado entre finales del siglo XVI y primeros años de la centuria siguiente. Nos preguntamos allí sobre la posible autoría de Loyola, dada las temáticas y espaciales que los une.

\section{Martín de Loyola por el mundo, hasta China (1580-1589)}

A principios de 1581, Loyola parte del puerto de Sevilla hacia México con un grupo de 26 franciscanos. Las intenciones son claras: evangelizar la sociedad china. Viaja en la flota española que llega a Veracruz para internarse en la ciudad de México, espacio de concentración de los misioneros que buscan a tierras asiáticas. Su estadía en México le permite conocer al padre agustino Juan

\footnotetext{
${ }^{6}$ GONZÁLEZ DE MENDOZA, Juan Historia de las cosas más notables, ritos y costumbres del gran reino de China, edición, prólogo y notas por Félix García, Aguilar, Madrid, 1985 [1944], pp. 312317.
} 
González de Mendoza, que se encuentra de regreso hacia España luego de fracasar en la conversión de asiáticos y en la creación de una embajada española en Oriente. Martín Ignacio tendrá la posibilidad de reencontrarse con el agustino en Roma, años más tarde, al visitar al Papa Gregorio XIII. Allí Loyola le entregará a González de Mendoza un escrito sobre su primer periplo por el mundo. Nos referimos al Itinerario, publicado como libro III en Historia de las cosas más notables, ritos y costumbres del gran reino de china, que se convertirá en uno de los manuscritos más famosos en Europa publicado por Juan González de Mendoza en $1585 .^{7}$

Luego de atravesar Nueva España de este a oeste, Loyola se embarca en marzo de 1582 en el galeón de Manila rumbo a las islas Filipinas. La comitiva franciscana la integran 18 frailes y algunos voluntarios. En el archipiélago hispano del Oriente, previa escala en las islas Marianas, los recibe el gobernador Gonzalo Ronquillo que pone trabas en el paso de los religiosos rumbo a Cantón. ${ }^{8}$ La relación se tensa. Ronquillo y su red familiar promocionan un comercio ilícito entre las islas Filipinas con el Perú, movilizando sedas chinas, azogue y hierro a cambio de la plata potosina. Preocupado por la economía de la Monarquía, Loyola denuncia entre sus pares la conducta de Ronquillo, porque el circuito de la seda china es una pieza ilícita en la economía por Hispanoamérica. En su Itinerario señala que "está usado en la gente de este reino [China] vestir seda como en Europa lienzo [...] hay tanta abundancia de ella, que salen cada año más de tres mil quintales, para Japón y más de quince navíos de ordinario para las Islas Filipinas". ${ }^{9}$ Como se verá más adelante, Loyola retomará el caso de la ruta hispanoamericana de la seda china al notar que sus efectos alcanzan a la misma Buenos Aires.

Junto con otros siete franciscanos, Loyola parte en junio de 1582 de Cavite hacia Macao. La unión de las dos Coronas en la persona de Felipe II es noticia entre los religiosos portugueses instalados en Asia. Pero los lusos no vendrán con buenos ojos el arribo de Loyola, más cuando lo nombran como

\footnotetext{
${ }^{7}$ El libro ofrece al Occidente una muestra de la cultura, sociedad, economía y política de China, con testimonios, experiencias, diarios y visitas. Entre 1585 y 1600 se llegan a publicar más de 40 ediciones en diferentes idiomas. GONZÁLEZ DE MENDOZA, Juan Historia..., cit., pp. 33-35. El título completo del escrito de Loyola es Itinerario y epitome de todas las cosas notables que hay desde España hasta el reino de China y de la China a España, volviendo por la India Oriental después de haber dado vuelta a casi todo el mundo y se ubica entre las páginas 299-396. Mendoza es el que confirma la autoría de Loyola: "Parece ser justo acabar esta segunda relación y dar principio a la tercera [...] y son dichas en sustancia y relación del mismo padre que las vio todas, llamado fray Martín Ignacio, el cual después de haber dado una vuelta al mundo, llegó aquí a Roma, con quien yo he hablado diversas veces", en GONZÁLEZ DE MENDOZA, Juan Historia..., cit., p. 297.

${ }^{8}$ Es el agustino González de Mendoza el que dice que los franciscanos "vencieron con sus ruegos y perseverancia" al gobernador para salir del archipiélago. GONZÁLEZ DE MENDOZA, Juan Historia..., cit., p. 344.

${ }_{9}^{9}$ GONZÁLEZ DE MENDOZA, Juan Historia..., cit., p. 357.
} 
primer custodio de la orden en el Oriente. En Malaca es recibido con tal hostilidad por los portugueses que lo obligan a retornar hacia Europa por la vía africana del Cabo de Buena Esperanza. Su destino final es Lisboa, en el trayecto conoce lugares como Goa, Madagascar y la costa de Guinea: el epicentro del tráfico ultramarino de esclavos destinados a los puertos de Veracruz, Cartagena y Buenos Aires. En su viaje de retorno piensa no solo en comunicar al Consejo de Indias y al Papa Gregorio XIII los conflictos vividos con los religiosos lusos, sino en ser reconocido como custodio legítimo de la orden para un segundo intento evangelizador en Asia.

\section{Mapa 1: Viajes de Martín Ignacio de Loyola}

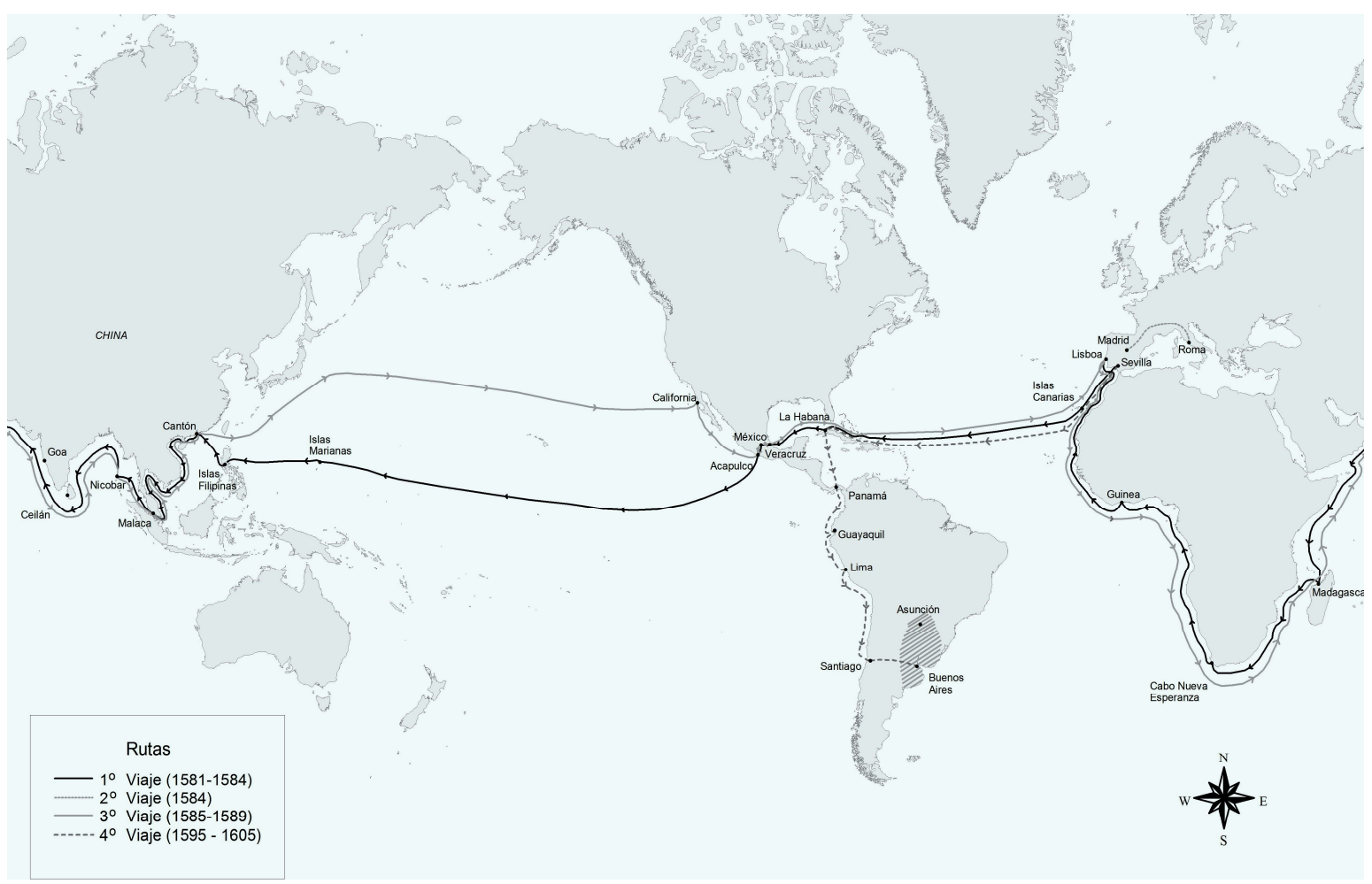

Fuente: Elaboración propia. Digitalización: Emelina Nava García

Las reuniones mantenidas con las autoridades de la Monarquía, con el padre general de la orden y con el Papa en la ciudad de Roma hacia 1584 le renuevan su energía para un segundo intento de cristianización en Asia. En esta ocasión, su periplo tomará una dirección inversa. Con el derecho de nombrar religiosos en el Oriente, Loyola parte en el mes de marzo de 1585 desde Lisboa hacia Malaca visitando lugares conocidos: Guinea y Goa. En su nueva estancia por Malaca se reiteran los conflictos con los portugueses, que lo consideran un "intruso", "frailecito" o "falso prelado". Las acusaciones se extienden cuando llega a Macao y a las islas Filipinas. ${ }^{10}$ A pesar de la unión de las coronas, las

10 TELLECHEA, Ignacio Martín Ignacio..., cit., pp. 39-41. 
fronteras se agudizan. ${ }^{11}$ Loyola no solo sufre la oposición de los portugueses, sino también de los jesuitas, de los teatinos e incluso de los chinos que se resisten a la conversión. El margen de acción de Loyola es francamente reducido. Así lo confiesa en varias de las cartas destinadas al virrey novohispano, marqués de Villamanrique. En sus líneas, se lamenta que su título de Comisario de los descalzos en China no sea respetado. ${ }^{12}$ Cuestionado desde varios frentes en el Oriente, decide renunciar definitivamente al proyecto evangelizador en China.

Loyola sale en julio 1587 desde la isla de Macarena, punto muy cercano a Macao, hacia México para llegar a España por la vía del Atlántico. Se embarca en la fragata Nuestra Señora de la Buena Esperanza con el capitán vizcaíno Pedro de Unamuno, descubridor que había caído preso en Macao por tráfico ilegal. El viaje transpacífico emula la derrota del galeón de Manila. Alcanza las costas de Alta California, donde la fragata realiza escalas en parajes y costas habitadas por indios y sin presencia española. El navío bordea el puerto de San Lucas, Valle de Banderas hasta arribar al puerto de Acapulco en noviembre. La travesía dura lo que en ese tiempo tarda el galeón oficial: 4 meses. Las experiencias que vive en el viaje transpacífico y en las costas occidentales de Nueva España se vuelcan en una Relación escrita por Unamuno donde Loyola participa en calidad de autor. Sería su segundo diario, después del Itinerario, sobre sus experiencias por el mundo. ${ }^{13}$

\section{Martín de Loyola en Sudamérica y Buenos Aires (1595-1606)}

Hacia mayo de 1595, seis años después de su segundo regreso de China, Loyola viaja hacia la Gobernación de Paraguay y Río de La Plata, a la que define como "la tierra más pobre y necesitada del mundo". Más que olvidada o región descuidada, el calificativo parece asociarse a la reciente refundación de Buenos Aires por Juan de Garay en 1580. Cuando llega el franciscano, habían pasado tan solo 15 años de aquél acontecimiento y para inicios de la década de 1590 la población residente en esa pequeña aldea se estima en 400 habitantes. Estamos lejos de una gran urbe, pero la considerable cantidad de población flotante que transita por el puerto (una cuarta parte de la población fija) nos advierte de un

\footnotetext{
${ }^{11}$ GRUZINSKI, Serge Las cuatro partes..., cit., p. 287.

12 Carta del virrey marqués de Villamanrique, México, 10 de diciembre de 1587, AGI, Audiencia de México (en adelante AGI, México), 21, N. 30.

${ }^{13}$ Relación del viaje y descubrimiento que hizo el capitán Pedro de Unamuno desde los puertos de Macan y Cantón hasta el puerto de Acapulco, México 20 de enero de 1588, AGI, México, 21, N. 29, fol. 1-4.
} 
espacio con elevado dinamismo de movilidad y clave en la geopolítica del escenario monárquico. ${ }^{14}$

Nombrado como custodio de la orden franciscana para la región, se propone continuar la tarea de conversión religiosa iniciada en China. En Sevilla se embarca en el galeón rumbo a Portobelo, con una numerosa comitiva de franciscanos. Llega a Nombre de Dios a finales del 1595. Estando en Panamá aborda un navío (¿la Armada del Sur?) surcando las costas del Pacífico hasta llegar al puerto de El Callao. Realiza una escala en Lima para observar la sociedad y la economía de la ciudad virreinal. El viaje continúa hacia el sur hasta la ciudad de Santiago. ${ }^{15} \mathrm{Su}$ paso por Chile no es solo una escala para llegar a la Gobernación de Asunción. Busca un encuentro con su primo hermano, Martín García de Oñez (1548-1598), que goza de una reconocida carrera política. Entre 1578 y 1581 su primo es nombrado corregidor de Potosí, Huamanga y Charcas; en 1586 de Huancavelica y en 1592 alcanza la gobernación de Chile, luego de un fugaz nombramiento como gobernador de Asunción. ${ }^{16}$ Loyola mantiene conversaciones con García de Oñez sobre la economía de Lima y el centro minero de Potosí que, por esos años, se encuentra en apogeo de su producción de plata. Desde Santiago cruza la cordillera de los Andes y llega a Buenos Aires hacia fines de 1596.

Instalado en el puerto del Río de La Plata, Loyola inicia los preparativos para la actividad misionera en las reducciones franciscanas, creadas desde 1580 entre los ríos de Paraná y Paraguay. Ante el panorama de escasez de recursos, gestiona un financiamiento real para poner en marcha la tarea de conversión. La turbulenta experiencia en tierras asiáticas, le recuerda lo protocolar que debe ser con sus pares políticos y religiosos. Emprende la navegación por los ríos y afluentes del Paraná, Uruguay y Paraguay para interiorizarse sobre la situación de los indios guaraníes. En su trabajo de campo por los valles fluviales de la cuenca del Río de La Plata y de Asunción estará acompañado por el gobernador Hernandarias, con quien edifica una relación amistosa y política durante su primer y segundo mandato. ${ }^{17}$

${ }^{14}$ GONZÁLEZ LEBRERO, Rodolfo La pequeña aldea. Sociedad y economía en Buenos Aires (15801640), Biblos, Buenos Aires, 2002, pp. 152-153.

${ }^{15}$ MOLINA, Raúl Fray Martín..., cit., p. 10. TELLECHEA, Ignacio Martín Ignacio..., cit., pp. 5859.

${ }^{16}$ La carrera político-militar de Martín García de Oñez toma impulso al participar en la victoria militar de 1572 contra Tupac Amaru. Termina casándose con Beatriz Clara Coya, la hija de Sayro Tupac, hermano de Tupac. Murió en 1598 en una guerra con los araucanos. ENCINA, Francisco Resumen de la Historia de Chile, Vol. I, Zig-Zag, Santiago, (1952) 1970, pp. 134-36.

${ }^{17}$ Hernandarias fue gobernador de Paraguay y Río de La Plata en 4 oportunidades: 1597-99, 1602-1609, 1615-1618 y la última sólo como gobernador de Paraguay y preso entre 1618-1621. Para mayores datos véase: BARRIERA, Darío “Un rostro local de la Monarquía Hispánica. Justicia y equipamiento político del territorio al sureste de Charcas, siglos XVI y XVII", Colonial Latin American Historical Review, Albuquerque, Spanish Colonial Research Center at the 
La vida de Loyola toma mayor protagonismo hacia el año 1600. A su nombramiento como custodio de la orden en la gobernación de Asunción y Río de La Plata, título con el que había llegado a Buenos Aires, se le suma, en 1603, el de obispo. ${ }^{18} \mathrm{Su}$ vida tomará un perfil más político que religioso, cuando el Cabildo de Buenos Aires lo nombre procurador del puerto para solicitar al Rey y al Consejo de Indias un permiso de apertura económica. No sabemos si Martín viaja hacia España directamente desde Atlántico o si decide repetir el clásico derrotero por el Pacífico con escala en Panamá. Lo que no reviste dudas son los objetivos profundos de su visita: formalizar el ingreso de Buenos Aires con recursos propios de la región al comercio exterior trasatlántico y así relajar su lazo de dependencia con el centro limeño y de Potosí.

\section{Loyola y la apertura oficial del puerto en 1602}

Por expreso pedido del gobernador Hernandarias, Loyola intentará convencer a Felipe III sobre la necesidad de institucionalizar las relaciones mercantiles entre Buenos Aires y los puertos de Brasil y con los de Guinea y Angola. Desde mediados del siglo XVI, con la inauguración del sistema monopólico de galeones, el puerto del Río de La Plata se encuentra cerrado como punto importador y exportador de mercancías y de plata. Su dinámica comercial está condicionada a los ritmos dictados por el centro de Lima. En 1594, 1595 y 1599 el Consejo de Indias emite disposiciones para que los vecinos de Buenos Aires acaten la prohibición. ${ }^{19}$ En ellas se recuerda la negativa al puerto para la introducción de esclavos africanos, de mercancías europeas y la correspondiente salida de plata potosina. La proyección oficial tiende a sujetar la cuenca del Plata dentro del eje limeño y, en el caso necesario, recurrir a licencias de navíos sevillanos permitidos por la Casa de Contratación para alcanzar de manera directa el puerto del Río de La Plata. ${ }^{20}$

University of New Mexico, vol. 15, núm. 4, 2006, pp. 377-418; TISCORNIA, Ruth Hernandarias estadista: la política económica rioplatense de principios del siglo XVII, Editorial Universitaria de Buenos Aires, Buenos Aires, 1973, pp. 34-58.

18 TELLECHEA, Ignacio Martín Ignacio..., cit., p. 71; GRUZINSKI, Serge Las cuatro..., cit., p. 284.

${ }^{19}$ Real Cédula al presidente y oidores de la Real Audiencia que reside en la ciudad de la Plata, de la provincia de los Charcas, la que "ordena que se cumpla la prohibición de 1594 y 1595 de no entrar por el Río de la Plata esclavos ni otras mercaderías de la corona de Portugal", San Lorenzo 18 de septiembre de 1596, AGI, Audiencia de Charcas (en adelante AGI, Charcas), 415, L. 2, fol. 110r-111r; Real Cédula a don Diego Rodríguez de Valdés, gobernador y capitán general de las provincias del Río de la Plata, que se manda que se "haga respetar la prohibición de introducir o sacar mercaderías, esclavos o pasajeros del Perú, por puertos de esas provincias", Aranjuez 16 de diciembre de 1599, AGI, Audiencia de Buenos Aires (en adelante AGI, Buenos Aires), 1, L. 4, fol. 184v-185r.

${ }^{20}$ MOUTOUKIAS, Zacarías Contrabando y control colonial en el siglo XVII. Buenos Aires, el Atlántico y el espacio peruano, Centro Editor de América Latina, Buenos Aires, 1988, pp. 70-71; GONZÁLEZ LEBRERO, Rodolfo La pequeña aldea... cit., pp. 75-76. 
En agosto de 1602, ya en España, le plantea al Consejo de Indias que el Río de La Plata carece de una "contratación formada", que le impide un desarrollo socio-demográfico y económico. Una hipotética apertura formal con Brasil y Guinea, según el obispo, no solo le inyectará vitalidad a la región, sino que funcionará como una barrera portuaria ante cualquier invasión de los extranjeros. Es necesario aprovechar su posición de nodo trasatlántico y disminuir su dependencia del polo limeño. Loyola propone oficializar su tráfico, otorgar licencias a propietarios para exportar productos locales hacia Brasil y Guinea e intercambiarlos por textiles, hierro y esclavos. En 1559 se había presentado al Consejo una propuesta similar que no tuvo éxito de materializarse. ${ }^{21}$ La intervención de Loyola, casi 43 años después, tiene mayor fortuna, posiblemente la confianza y estrecho lazo que tuvo con la Corona en su etapa por China inclinaron a que su proyecto sea considerado. Si el 9 de agosto de 1602 presenta la idea solo 10 días después, el 20 de agosto, Felipe III la aprueba con importantes condicionantes.

“Real Cédula en la que se autoriza a los vecinos de la ciudad de La Trinidad, y puerto de Buenos Aires, de las provincias del Río de la Plata, a que, por el término de 6 años, exporten harina, cecina y sebo al Brasil, Guinea y otras islas circunvecinas, y el trueque de esos productos por otros indispensables para el consumo en dicha ciudad, con prohibición de sacarlos a ninguna otra parte de las Indias" ${ }^{22}$

Con navíos propios de los vecinos de la ciudad, la Corona permite exportar por Buenos Aires 2 mil fanegas de harina, 500 quintales de cecina y 500 arrobas de sebo al año hacia Brasil y costas e islas de África. Como contrapartida, autoriza la importación de textiles ultramarinos y otros productos producidos en Brasil. Rechaza la "contratación formada", esto es: el ingreso de españoles, esclavos africanos y salidas de plata potosina. Loyola aumenta su poder de influencia en la gobernación. No solo es el responsable de la medida, sino que se le concede por mandato real la facultad de otorgar permisiones navieras en acuerdo con el gobernador Hernandarias. La Audiencia de Charcas se encargaría de evitar que el comercio triangular por el Atlántico ocasione daños al tráfico hacia la economía interior de la gobernación de Tucumán y Charcas. Si bien la cédula de 1602 ordena la emisión de licencias

\footnotetext{
${ }^{21}$ La propuesta lleva por título "Necesidad que tienen los moradores de Buenos Aires de importar del Brasil varias cosas para su sustento". DE SOLANO, Francisco "Contactos Hispanoportugueses en América a lo largo de la frontera brasileña (1500-1800)," en DE SOLANO, Francisco y BERNABÉU, Salvador (coords.) Estudios (nuevos y viejos) sobre la Frontera, Consejo Superior de Investigaciones Científicas, Madrid, 1990, p. 204.

22 Valladolid, 20 de agosto de 1602, AGI, Buenos Aires, 1, L. 4, fol. 190r-191v.
} 
para un período de 6 años, futuras disposiciones de 1608 y 1614 extienden la permisión hasta $1618 .^{23}$

La Cédula de 1602 no solo es importante en lo comercial: despunta efectos políticos y sociales en la región. Antes, las autorizaciones para el comercio directo con Buenos Aires recaían en los comerciantes sevillanos, fiscalizados por la Casa de Contratación. La real cédula de 1594 clausura todo comercio con Buenos Aires "que no partiese de Sevilla en navíos despachados por la Casa de Contratación". ${ }^{24}$ Por el contrario, la nueva permisión de 1602 permite a "los vecinos de la ciudad de Trinidad" realizar el comercio trasatlántico con sus propias embarcaciones con Brasil y África, sin depender de los mercaderes de Sevilla y menos aún de los más antiguos grupos de comerciantes del Alto Perú o del Tucumán. ${ }^{25}$ ¿Estamos ante el germen constitutivo de una elite local comercial-ganadera distanciada de los intereses del eje Sevilla-Lima? Difícil diferenciar los perfiles de elite cuando sabemos de la coexistencia en el puerto de mercaderes del Potosí (sean portugueses o españoles) y agentes dedicados al sector ganadero. El escenario se torna aún más difuso cuando el hilo fino entre lo legal e ilegal se quiebra de manera recurrente. ${ }^{26}$

Aun reconociendo el trato informal por Buenos Aires, el cuadro 1 muestra que los años 1601-1605 representan un parte-aguas en el movimiento económico de Buenos Aires con las costas del Brasil. Se incrementan más del $60 \%$ las llegadas y partidas de navíos; el valor registrado de las importaciones pasa de 16 mil a 130 mil pesos y se duplica el valor de lo exportado: de $30 \mathrm{mil} \mathrm{a}$ 63 mil pesos. Si bien no aparecen datos de las importaciones de esclavos, todo indica que su incremento informal también se elevó. Dos razones íntimamente vinculadas podrían explicar este espectacular incremento: a) la puesta en

\footnotetext{
${ }^{23}$ Real Cédula en la que se prorroga por dos años más la licencia que se dio a la ciudad de La Trinidad, puerto de Buenos Aires, para sacar cierta cantidad de sus frutos al Brasil, Guinea y otras islas circunvecinas y retornar con otros que sean para consumo de esa provincia, San Lorenzo 19 de octubre de 1608, AGI, Buenos Aires, 1, L. 4, fol. 207v-212r; Real Cédula en la que se prorroga por tres años más la licencia que se dio a la ciudad de La Trinidad, puerto de Buenos Aires, para sacar cierta cantidad de sus frutos al Brasil, Guinea y otras islas circunvecinas y retornar con otros que sean para consumo de esa provincia, San Lorenzo 19 de julio de 1614, AGI, Buenos Aires, 1, L. 4, fol. 224v-226r.

${ }^{24}$ Real Cédula al presidente y oidores de la Audiencia Real de la ciudad de la Plata, de la provincia de los Charcas, noviembre de 1594, AGI, Charcas, 415, L. 2, fol. 110-111.

${ }^{25}$ Real Cédula en la que se autoriza a los vecinos de la ciudad de La Trinidad, y puerto de Buenos Aires, de las provincias del Río de la Plata, agosto de 1602, AGI, Buenos Aires, 1, L. 4, f. 190.

${ }^{26}$ Juan de Vergara, Mateo Leal de Ayala y el portugués Diego de Vera constituyen los casos más importantes de la nueva elite porteña. GELMAN, Jorge "Economía natural-economía monetaria. Los grupos dirigentes del Buenos Aires a principios del siglo XVII", Anuario de Estudios Americanos, Sevilla, núm. 44, 1987, pp. 1-19; CANABRAVA, Alice O comércio português no Rio da Prata (1580-1640), Universidad de Sao Paulo, Belo Horizonte, 1984, pp. 23-65.
} 
ejecución de la Real Cédula del año 1602; b) la política económica de blanqueo y combate al contrabando, característica distintiva del gobierno de Hernandarias, aliado del Loyola.

\begin{tabular}{cccccc} 
Cuadro 1: Movimiento comercial por Buenos Aires, 1585-1615 \\
& & NAVÍOS DESDE Y HACIA LAS COSTAS DE BRASIL & \\
\cline { 2 - 6 } QUINQUENIO & LLEGADAS & ZARPADAS & VALOR & VALOR & ESCLAVOS \\
& & & IMPORTADO & EXPORTADO & \\
\hline $1585-1590$ & 10 & 1 & 17.661 & 10.576 & 3 \\
$1591-1595$ & 29 & 1 & 192.961 & 19 & 228 \\
$1595-1600$ & 27 & 33 & 16.063 & 30.735 & 49 \\
$\mathbf{1 6 0 1 - 1 6 0 5}$ & $\mathbf{4 1}$ & $\mathbf{5 2}$ & $\mathbf{1 3 0 . 4 0 4}$ & $\mathbf{6 3 . 4 4 4}$ & - \\
$1606-1610$ & 57 & 37 & 306.641 & 61.020 & 859 \\
$1611-1615$ & 80 & 45 & 635.000 & 54.329 & 3.815
\end{tabular}

Fuente: Moutoukias, Zacarías Contrabando..., cit. $^{27}$

La real cédula de 1602 promueve la economía del puerto: entre 1603 y 1655 se efectúan cerca de 70 embarques de cecina desde el Río de La Plata hacia Brasil y África occidental. ${ }^{28}$ ¿Es apresurado pensar que la medida oficial representa el más temprano antecedente del modelo exportador ganadero en la región de Buenos Aires; engranaje central de lo que sería más adelante la economía nacional Argentina? Arriesgada hipótesis. Lo cierto es que la cédula de1602 constituye el primer instrumento legal tendiente a una mayor autonomía de la Gobernación con relación a Lima y aún a Sevilla.

Ahora bien, ¿hasta qué punto la propuesta de Loyola promueve la "independencia" mercantil de la región del Río de La Plata? No hay que olvidar que la emisión de la cédula se efectúa en el marco de un vigoroso mercado interno peruano, donde Lima y Potosí constituyen los polos de desarrollo. Charcas, la Gobernación de Tucumán y aún el Río de La Plata forman parte de la red de circuitos del espacio peruano. ${ }^{29}$ Las economías regionales proveen a aquellos polos, en calidad de centros consumidores, bienes locales pero también bienes europeos funcionando como espacios de escala en su circulación. Buenos Aires, punto de ingreso clandestino de mercancía europea responde a la demanda de los mercados internos del espacio. De tal manera, el rasgo preeminente de Buenos Aires para la época es la de ser un puerto

\footnotetext{
${ }^{27}$ Los datos son recogidos de la antigua revista Registro estadístico del estado de Buenos Aires, José María Trelles (dir.), Buenos Aires, Imprenta Argentina "El Nacional".

${ }_{28}$ MONTOYA, Alfredo Historia de los saladeros argentinos, Raigal, Buenos Aires, 1956, p.11.

29 ASSADOURIAN, Carlos Sempat El sistema de la economía colonial. Mercado interno, regiones y espacio económico, Instituto de Estudios Peruanos, Lima, 1982; GARAVAGLIA, Juan Carlos Mercado interno y economía colonial. Tres siglos de historia de la yerba mate, Grijalbo, México, 1983.
} 
clandestino. Las importaciones de esclavos, de textiles suntuosos europeos, de hierro con la correspondiente salida de monedas de Potosí como forma de pago hacen al sentido mercantil del puerto. La Cédula de 1602, que tiende a la orientación de la economía rioplatense hacia el Brasil, parece no tener la capacidad para quebrar un modus operandi de Buenos Aires. De ahí la continuidad de su actividad portuaria operando a modo de puerto contrabandístico.

Por su parte, también encuentra límites el "éxito" alcanzado por Loyola y Hernandarias en la relación de Buenos Aires con el Brasil. A pesar de la vigencia de la disposición de 1594 que combate el contrabando, el movimiento de esclavos, textiles y plata por el puerto funciona en plenitud. Portugueses, españoles residentes o venidos desde el interior participan en el intercambio ilegal de esos bienes. ${ }^{30}$ El trato con Brasil y aún con África se asienta, ante todo, en la importación de esclavos. También son regulares los barcos procedentes de Lisboa que, previa escala en las costas de África, se dirigen a Bahía, Pernambuco y Buenos Aires para ingresar la mano de obra esclava y los textiles europeos y orientales. Los esclavos representan casi el 70\% de las importaciones de Buenos Aires, valor que se incrementa conforme avanza el siglo XVII. ${ }^{31}$

La importación de esclavos arroja una enorme rentabilidad para los agentes instalados en Buenos Aires. Desde Brasil se ofrecen esclavos y textiles que exige Buenos Aires. Desde el puerto se oferta, como medio de pago, cecina, harina, sebo y otras producciones locales. Brasil acepta productos de la tierra para saldar aquellas importaciones ultramarinas; elemento distintivo de los intercambios oficiales que subordinan a Buenos Aires con Córdoba, Santa Fe, el Alto Perú y aun con Lima donde la plata es fundamental. ${ }^{32}$ Es evidente que la cédula de 1602 tiende a la disminución del movimiento clandestino de producciones locales con Brasil. Pero la introducción de esclavos africanos y productos europeos, es incapaz de saldarse con productos de la tierra. Termina por intensificar las salidas de plata clandestinas por el puerto. Esclavos y plata

\footnotetext{
${ }^{30}$ La práctica ilegal no es difícil si se parte del hecho que se realiza con embarcaciones de pequeño porte que rondan entre 20 y 50 toneladas. MOUTOUKIAS, Zacarías Contrabando..., cit., pp. 62-63; CANABRAVA, Alice O comércio..., cit., pp. 67-90.

${ }^{31}$ GELMAN, Jorge "Economía...", cit., pp. 6-7; SAGUIER, Eduardo "Commercial Cycles and Intracolonial Struggles in an Entrepot Economy Under Habsbourg Mercantilism: Buenos Aires in the Seventeenth Century", tesis doctoral, Saint Louis, Washington University, 1981, pp. 239256.

${ }^{32}$ GONZÁLEZ LEBRERO, Rodolfo La pequeña..., cit., pp. 76-77. Moutoukias ofrece un caso muy representativo para años posteriores (1617), pero útil aquí para reconocer lo redituable que resulta a Buenos Aires formalizar el trato con el espacio lusitano. En Buenos Aires 2 mil fanegas de harina, 8.500 quintales de cecina y 500 arrobas de cebo alcanzan un valor total de 12.500 pesos. En Brasil, estas mercancías se pueden trocar por mercancía ultramarina a 24 mil pesos, las que finalmente se expenden en Buenos Aires a 50 mil pesos. MOUTOUKIAS, Zacarías Contrabando..., cit., pp. 63-64.
} 
serán los principales productos de intercambio por el puerto durante las primeras décadas del siglo XVII. La ciudad de Córdoba no es solo un espacio proveedor de textiles locales para hacia el Alto y centro del Perú; ante todo, fungirá como centro redistribuidor de esclavos africanos que llegan por Buenos Aires. ${ }^{33}$ Las numerosas solicitudes de Buenos Aires o Córdoba por legalizar el tráfico de esclavos, desde Brasil o de la Guinea africana son rechazadas dada la succión de plata que demandan. Las pocas permisiones no alcanzan para detener el sistemático flujo de esclavos y plata. $^{34}$

\section{El pensamiento global de Loyola y su crítica a los monopolios}

El esfuerzo de Loyola por garantizar el desarrollo de Buenos Aires no se reduce a la Cédula de 1602. A partir de entonces, fundamenta con argumentos globales el mantenimiento de la concesión otorgada por la Corona. En cartas que envía a Felipe III muestra la conexión entre lo que sucede por el Río de La Plata con fenómenos que nacen de la misma China. Comunica que "ha entrado tanta ropa de la China en el Perú de contrabando que no hay provincia por acá que no esté llena de ella, y tan buena y barata que las cosas de España ya no valen nada". ${ }^{35}$ Es un intento por convencer que el comercio por Buenos Aires no es perjudicial el intercambio trasatlántico por Panamá. Más bien, la crisis económica que atraviesa la feria del istmo recae en el comercio ilícito del Perú por el Pacífico, pues "la centésima parte de la ropa que este año [1605] ha entrado en el Perú, es más que cuanta ha entrado por este puerto en 50 años". ${ }^{36}$ No es el comercio de bienes locales que salen por el Río de La Plata lo que hace peligrar al comercio "de Tierra Firme y Nombre de Dios", sino los "muchos millones de pesos que van a las Filipinas" desde las costas de Perú, en particular desde su puerto de El Callao. ${ }^{37}$ Loyola arroja una precisa cifra de plata potosina que escapa ilegalmente hacia el Pacífico y China: "llevan del Perú cada año 2 millones de plata que va a pasar a la China". ${ }^{38}$ La plata peruana converge en Acapulco con la mexicana en su salida hacia el Oriente con el galeón de Manila. Calcula, según Loyola, que “entre la Nueva España, Perú y Filipinas, se llevan cada año

\footnotetext{
33 Desde el Río de La Plata los esclavos toman dos derroteros: el más frecuente rumbo al Alto Perú y en menores proporciones a Chile con escala en Mendoza. Hacia el final del primer cuarto del siglo XVII Córdoba cambiará su estructura económica al convertirse en espacio monoproductor de ganado, en especial de mulas que se utilizará como medio de transporte para el trabajo en las minas. ASSADOURIAN, Carlos El sistema..., cit., pp. 85-90.

${ }^{34}$ Véase cada una de ellas en DE SOLANO, Francisco "Contacto...", cit., pp. 204-205.

${ }^{35}$ BONIALIAN, Mariano China..., cit., pp. 105-106.

${ }^{36}$ Que se tripliquen los despachos tocantes a la contratación con las Filipinas y a las mercaderías y ropa de la China que se prohíben en el Perú, Buenos Aires, 6 de mayo de 1605, en AGI, Charcas, 135, fol. 1.

${ }^{37}$ Carta del 13 de febrero de 1603, en MOLINA, Raúl Martín Ignacio..., cit., p. 47.

${ }_{38}$ Carta de Martín Ignacio de Loyola, obispo del Rio de la Plata, al presidente del Consejo adjuntándole memorial sobre Filipinas, sin fecha, AGI, Filipinas, 35, N. 47, fol. 823v.
} 
3 o 4 millones de plata lo que todo va a poder de los chinos". ${ }^{39}$ Es conocedor de ello por ser "testigo de vista, que vi una vez en el Callao una nao con mercaderías de la China que valía más que cuanto ha entrado por este puerto de Buenos Aires en cincuenta años y más que vale toda esta provincia". ${ }^{40}$ Mencionamos que Loyola había conocido las prácticas comerciales ilícitas del gobernador de las islas Filipinas, Gonzalo de Ronquillo, desde su primer viaje a China. En 1580, en pleno contexto de prohibición para el trato entre Perú y China, Ronquillo decidió enviar hacia El Callao el navío Nuestra Señora de la Cinta colmado de sedas, hierro y especiería. El navío retornó al archipiélago con plata potosina. En 1581 Ronquillo volvió a practicar el contrabando con el Perú, esta vez a través de su sobrino. ${ }^{41}$ ¿La relación con el gobernador se había tensado aún más al reconocerlo como el jefe de una red de contrabando de bienes chinos hacia el Perú? Puede ser.

Loyola alude a la movilidad de los peruleros para demostrar cómo la economía del Perú se orientaba hacia el polo asiático en detrimento de Portobelo. Los peruleros son una suerte de comisionistas y factores de los grandes mercaderes limeños que viajan hacia la Nueva España, Filipinas o China cargados con monedas de plata para la compra de seda, porcelanas y otros productos del Oriente. Negocian con los comerciantes mexicanos y capitanes de la nao de China para embarcarse hacia los mercados del Oriente y realizar rentables intercambios. Tienen la puerta abierta del archipiélago hispano gracias al favor del propio gobernador de la isla: Gonzalo Ronquillo. ${ }^{42}$ Es tanta la estimación que presenta el mercado del Perú por la seda oriental, que por estas décadas que escribe Loyola nace y florece una ruta de la seda china entre México y Panamá y el Perú, alcanzando Buenos Aires. ${ }^{43}$ Su conclusión es contundente: el eje del Pacífico compuesto por Perú, Nueva España, Filipinas y China hace peligrar "la dependencia y subordinación" del virreinato andino hacia España. ${ }^{44}$ Notable visión global: de lo económico a lo político, de la defensa a Buenos Aires a los escapes de plata peruana a China dejando en vilo el dominio de España sobre las Indias. Buenos Aires, más que

\footnotetext{
${ }^{39}$ MOLINA, Raúl Martín Ignacio..., cit., p. 47.

${ }^{40}$ MOLINA, Raúl Martín Ignacio..., cit., p. 47.

${ }^{41}$ Comercio de Filipinas con Perú, Lisboa 11 de junio de 1582, AGI, Filipinas, 339, L. 1, f. 210v$211 r$.

42 Loyola: “...que como los mexicanos y peruleros envían tanta plata ha subido el precio de las sedas y mercaderías de la China de tal suerte que han aumentado a mil por ciento las mercaderías, con harto de las filipinas; y así es ciertísimo que concediéndoles que solo ellos traten con una limitación justa, ellos solos querían ser los gananciosos y procurarán que no envían plata los mexicanos y peruleros", Documentos sobre el comercio de Filipinas, 1602, AGI, Filipinas, 35, N. 47, fol. 823-24v.

43 BONIALIAN, Mariano China..., cit., pp. 87-106.

${ }^{44}$ Documentos sobre el comercio de Filipinas, 1602, AGI, Filipinas, 35, N. 47, fol. 823-24v.
} 
concebirla como una puerta competitiva de Panamá, la concibe como el espacio que le dará equilibrio y estabilidad a la Monarquía.

Con el caso de los portugueses, Loyola se consagra como una de las personalidades políticas más influyentes de la región. Se muestra muy prudente a la hora de aplicar la real cédula de 1601 y reiterada en 1603 ordenando la expulsión de los portugueses residentes en Buenos Aires. ${ }^{45}$ La persecución existe desde la segunda mitad del siglo XVI. ${ }^{46}$ Loyola abandona la posición de religioso católico al reconocer la función central de los lusos para un puerto que vive de la población flotante y su perfil permeable al foráneo. Es consciente de que el desarrollo del puerto se encuentra condicionado a la participación de los portugueses, no solo en su comercio con Brasil y Guinea, sino por sus iniciativas en la actividad agrícola y artesanal. En 1601, le comunica a Felipe III que, en primer lugar, el ingreso de portugueses por el Río de La Plata es minúsculo en relación a "toda clase de gentes" que transitan sin licencia por Nombre de Dios, Panamá y San Juan de Ulúa. Por Panamá ingresan más portugueses en un año que por el Río de La Plata durante 50 años. ${ }^{47}$ La comparación y cotejo de lo que ocurre en otras zonas de Hispanoamérica es la estrategia discursiva más recurrente en Loyola para fundamentar la presencia portuguesa.

Con "cintura política", Loyola toma el caso portugués y desafía la posición de la Monarquía y de Hernandarias. Sin pensar en los costos sociales y económicos, el gobernador se encuentra decidido por cumplir con la decisión real de expulsión, con la excusa de las responsabilidades de los portugueses en el contrabando. En 1603, decide la expulsión de más de 40 portugueses. La medida rompe vínculos familiares y de parentesco. La población del puerto acude al franciscano como mediador y arbitrista para visibilizar su reclamo. Loyola expone al Cabildo de Buenos Aires sobre la necesidad del uso de la epikeia o de la equidad para la interpretación de leyes restrictivas de la Monarquía. ${ }^{48}$ Argumenta que si se lleva a cabo la expulsión sumergiría "al campo y a las industrias a su ruina", panorama opuesto a los objetivos que

\footnotetext{
${ }^{45}$ Le ordena expulsar a los portugueses, a los extranjeros, y a todos aquellos que hubieren entrado por el Río de la Plata sin licencia, Real Cédula al corregidor de la villa imperial de Potosí, Valladolid 6 de abril de 1601, AGI, Buenos Aires, 2, L. 5, fol. 13. La orden de 1603 es mencionada en MOLINA, Raúl Fray Martín..., cit., pp. 46-51.

${ }^{46}$ Real Cédula al presidente y oidores de la Audiencia de Tierra Firme, para que se informen de los portugueses y gitanos que residan en aquella tierra, y expulse de ella a todos los que estuvieran sin licencia real, y que no se les permita quedarse bajo ningún concepto, Madrid 15 de julio de 1568, AGI, Audiencia de Panamá (en adelante AGI, Panamá), 236, L. 10, fol. 113v$114 r$.

${ }^{47}$ Carta de Fray Martín Ignacio de Loyola, obispo del Río de la Plata, sobre la gente de toda clase que entra en las Indias sin tener licencia, provenientes en su mayor parte de Nombre de Dios, Panamá y San Juan de Ulúa, AGI, Panamá, 15, R. 2, N. 12, s/n de fol.

${ }^{48}$ MOLINA, Raúl Fray Martín..., cit., pp. 32-34; TELLECHEA, Ignacio Martín Ignacio..., cit., pp. 79-80.
} 
aspira el monarca. Había que suspender la orden de 1603 hasta tanto la ciudad se encuentre plenamente poblada y fortalecida. Tanto el Cabildo, el propio Hernandarias y el mismo rey aceptan la postura de Loyola y desisten de ejecutar la medida. La intervención política de Martín Ignacio en el caso portugués habría facilitado el consenso político en los primeros tiempos del segundo mandato de Hernandarias (1602-1609).

Por otro lado, Loyola critica los monopolios y a los poderes políticos enquistados en la ciudad de México y de Lima. Pregona por la libertad comercial y una mayor atención a rincones marginados por la política de la Monárquica. Su pensamiento es revolucionario para la época: nos recuerda a las políticas aplicadas por el "reformismo borbónico" de la segunda mitad del siglo XVIII. Un siglo y medio antes, Loyola advierte del peligro que los notables de México y de Lima concentren tanto poder, lo que podría provocar "la independencia que se va siguiendo al Perú y México de España”, llegando "el día que las Indias no estuvieren pendientes de España en todo sin duda se destruirá toda la política espiritual y temporal" ${ }^{49}$

La visión vanguardista asoma en varios temas. Sus viajes a las islas Filipinas y China le permiten conocer la actividad de los mercaderes de México sobre el mercado asiático. Los capitanes de los galeones son los verdaderos dueños de las boletas de carga, que las distribuyen posteriormente a los comerciantes mexicanos y peruanos para adquirir bienes chinos en sus viajes transpacíficos. Poco se cumplía la ley sobre la exclusividad que deberían tener los vecinos de Manila como cargadores de la nao. Loyola no duda: "el remedio propio que tengo consiste en que se haga un consulado en Manila"; ${ }^{0}$ un cuerpo mercantil que tenga independencia con respecto a México. La idea de Loyola recién se podrá materializar casi dos siglos después, en 1769 (i!), en pleno contexto de las políticas de libre comercio borbónicas. El caso de México y Filipinas no resulta tan distante del análisis que realiza Loyola sobre el Perú, Chile y Buenos Aires. Si bien no menciona la creación de un consulado porteño, sí recomienda mayor autonomía del Río de La Plata con relación al centro político del virreinato: Lima. Tucumán debería tener un gobernador, Paraguay un obispo independiente. Loyola también defiende a Chile. En una carta dirigida al Rey desde su paso por Lima en 1596, informa que, aún con la "indiferencia que muestra Perú", Chile "nunca estuvo en tan buen punto como el que ahora tiene y esto ha sido sin que el virrey del Perú le haya favorecido". Le recomienda al Rey darle a Chile una mayor atención a sus capitanes y gobernadores. ${ }^{51}$ En definitiva, el análisis sobre la economía de Buenos Aires es la muestra más clara de su cosmovisión global, evitando caer en visiones

\footnotetext{
${ }^{49}$ Cartas y expedientes de los obispos y arzobispos de Charcas, AGI, Charcas, 135, fol. 1.

${ }^{50}$ Documentos sobre el comercio de Filipinas, 1602, AGI, Filipinas, 35, N. 47, fol. 824.

${ }^{51}$ TELLECHEA, Ignacio Martín Ignacio..., cit., pp. 59-60.
} 
locales. La inscribe sobre lo que sucede en Potosí, Brasil, África (costa de Guinea), Portobelo (Nombre de Dios), España, México, islas Filipinas y la misma China. Todo espacio del planeta tiene una relación con Buenos Aires. Para Loyola, la temprana Buenos Aires se comprende solo si se inscribe en el tablero geopolítico y económico mundial $\mathrm{y}$, a la inversa, la temprana globalización no estaría completa si se desconoce al puerto.

\section{Loyola y un boceto de la Gobernación de Asunción y Río de La Plata}

En el Archivo General de Indias de Sevilla (AGI) se encuentra una cartografía, un boceto, que llama la atención por la cercanía temática con el pensamiento y la actuación de Loyola. Lleva como clasificación documental "MP-Buenos Aires, 5", titulado: Mapa y derroteros del Océano Atlántico y costas aledañas. No presenta fecha, aunque como expresa el documento: "por la letra parece del siglo XVI". $\mathrm{Su}$ confusa rúbrica no permite identificar al autor. Presenta el subtítulo: Comprende las costas atlánticas de Europa sudoccidental, África (hasta el Golfo de Guinea) y América (a excepción del extremo norte), aproximadamente desde los $50^{\circ} \mathrm{N}$ hasta los $56^{0}$ S. También plasma el contorno de Centroamérica y Sudamérica a orillas del Pacífico. El Océano Atlántico es designado Mar de España. El portal web del Archivo http://pares.mcu.es y su pestaña unidades relacionadas por procedencia ofrece datos adicionales. La pestaña remite al ramo Indiferente, vol. 1528, exp. 30. Allí se lee un brevísimo documento de solo dos fojas. La primera señala: Mapa y derroteros de la América Meridional y Golfo de México. La mención "Golfo de México" es discutible pues son costas con nula atención en la ilustración. El virreinato cuenta con solo dos referencias: Nueva España y Yucatán. La segunda foja está en blanco.

El incógnito autor envía el mapa (ver Mapa 2) rumbo a España, para llegar a manos del Monarca y del Consejo de Indias. Al dorso de la ilustración escribe: "Perdone vuestra señoría la mala mano que hacelo, como nunca me enseñaron el oficio de pintor, pero allá se podría por esa traza hacer pintar bien a quien lo supiese hacer." ${ }^{2}$ Más que un cartógrafo, el responsable parece ser una personalidad política o religiosa del Río de La Plata y Paraguay, con confianza en compartir el boceto con las máximas autoridades de la Monarquía. Como se verá, son varias razones que ligan el boceto con la vida de Loyola, que incluso llevan a pensar en su posible autoría. Pero lejos están de ser contundentes, más aún si notamos que el mapa pudo realizarse 15 años antes de su arribo al puerto. Más allá de las dudas, lo que interesa demostrar es la relación que existe entre Loyola y el rico contenido histórico que ofrece la ilustración.

${ }^{52}$ Mapa y derroteros del Océano Atlántico y costas aledañas, AGI, MP-Buenos Aires, 5, fol. 2. 


\section{Mapa 2: de las misiones franciscanas y de Buenos Aires}

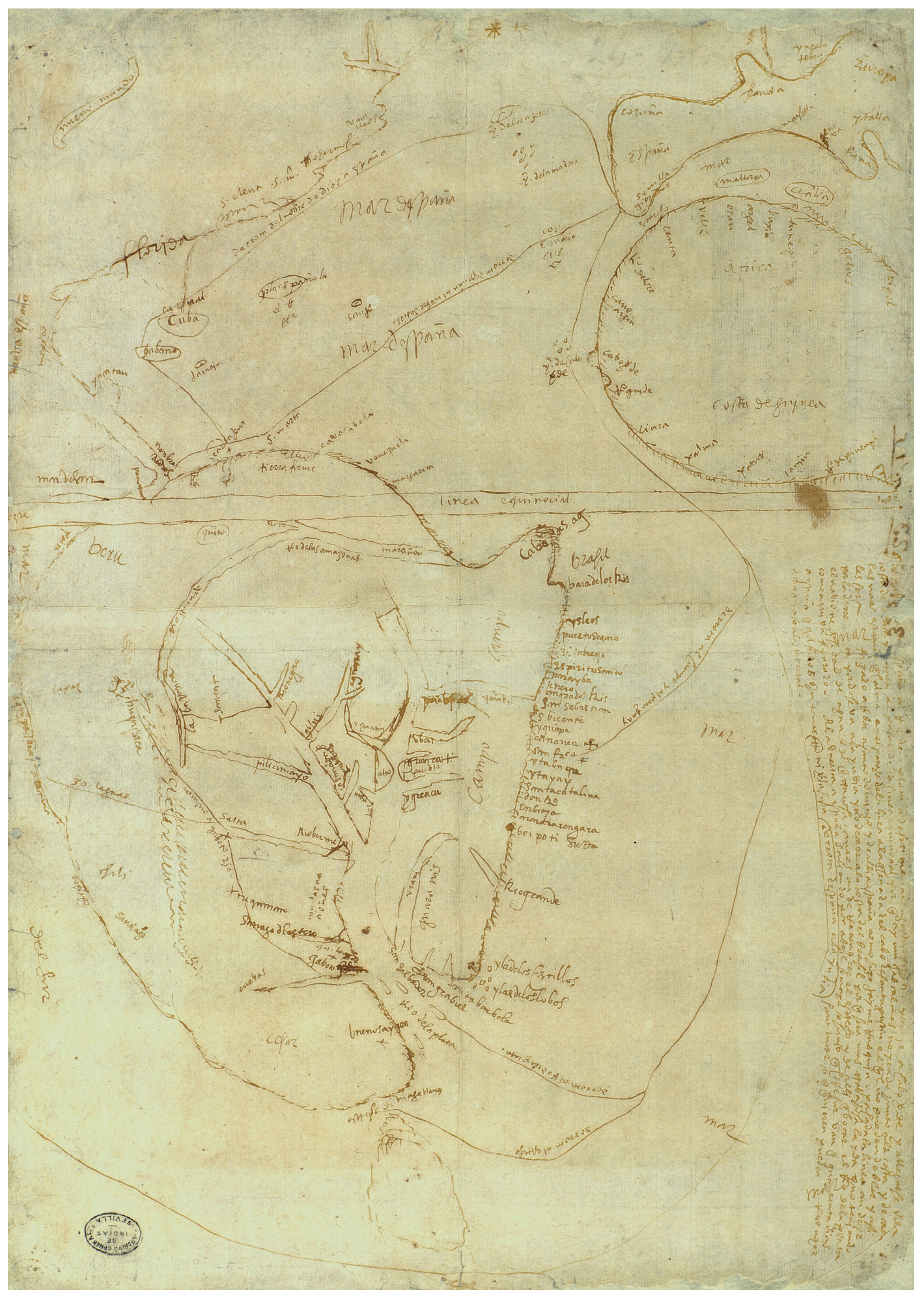

Fuente: AGI, Mapa y derroteros del Océano Atlántico y costas aledañas, MP-Buenos Aries, 5. 
En primer lugar, en el Itinerario a China que mencionamos en páginas anteriores, Loyola exhibe percepciones espaciales muy similares a las que aparecen en el mapa. Al testimoniar su llegada a México desde Sevilla en su primer viaje, expone una singular inscripción geográfica del virreinato novohispano en el Orbe Indiano.

“Está este Reino [México], por la parte de Oriente, pegado con la tierra del Perú, y así corriendo por el mar del Norte se va a dar a Nombre de Dios, que es puerto del mismo reino, y yendo desde el de Acapulco, que es en el de México y en la mar del Sur, se va a dar a Panamá, puerto asimismo del dicho Perú y en la dicha mar, cerca del estrecho de Magallanes y no muy lejos del Río de la Plata y el Brasil."53

Al margen de las falsas dimensiones espaciales, propias de un Nuevo Mundo ${ }^{54}$ recientemente descubierto, el espacio local sea Río de La Plata (mapa) o Nueva España (Itinerario) es suscrito en las más amplias fronteras de la monarquía y aún del globo. En ambos documentos, Nueva España se encuentra "pegado" al reino del Perú. Centroamérica se minimiza al notar que, por el Mar del Norte, el golfo de México "se va a dar" a Nombre de Dios. Las imaginarias cercanías entre espacios son más notables para la América meridional: Panamá está próximo al Río de La Plata, al Brasil e incluso al estrecho de Magallanes.

Partiendo que la ilustración magnifica y minimiza espacios regionales, oceánicos y continentales, lo cierto es que la atención primaria se concentra en el área de los actuales territorios de la Mesopotamia Argentina, desde el puerto de Buenos Aires pasando por Iguazú, sudeste de Paraguay, sudoeste brasileño y parte occidental de Uruguay (Mapa 3). En ella se desarrollaron las primeras misiones franciscanas, previo a las conocidas reducciones de los jesuitas. Puede suponerse que el mapa es una herramienta cartográfica propia de los franciscanos y autoridades políticas de la gobernación, surgida a partir de un "trabajo de campo" que estudia centros poblaciones, circuitos de navegación, fluviales y reducciones.

\footnotetext{
${ }^{53}$ GONZÁLEZ DE MENDOZA, Juan Historia..., cit., Libro tercero, Capítulo V, p. 311

${ }^{54}$ El término aparece en la parte superior izquierda de la ilustración.
} 


\section{Mapa 3: Área Geográfica actual de las misiones franciscanas}

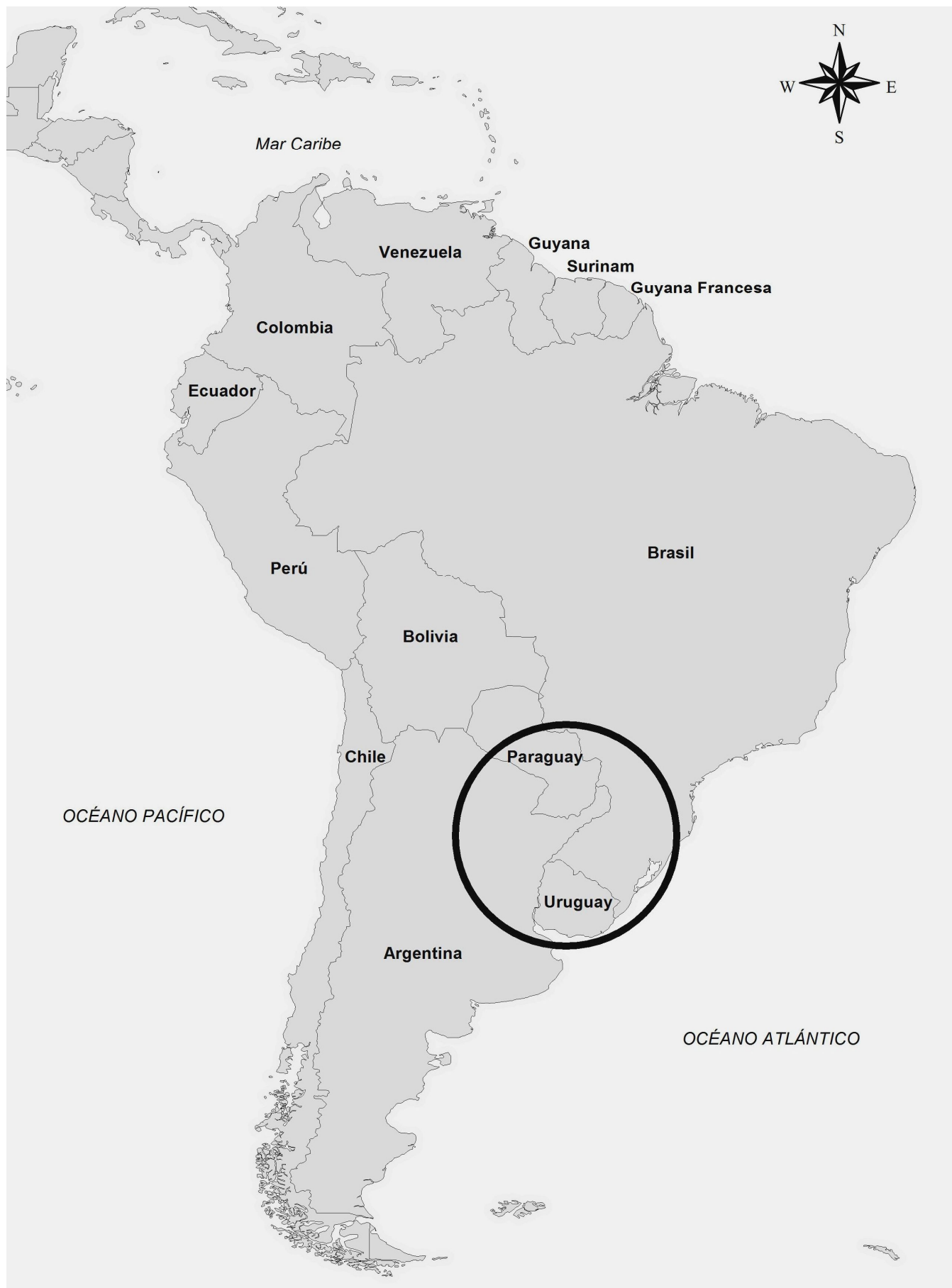

Fuente: elaboración propia. Digitalización Emelina Nava García

El sistema de reducción se ubica entre los ríos Paraguay y Paraná. Por el lado este, los afluentes del río Paraguay son, el río Negro en el norte y Jejuí, referencia esta última que podría apuntar al propio río o a la reducción franciscana fundada en 1580: Jejuy. Se dibuja un pequeño afluente sin nombre 
entre ambos cursos fluviales: ¿río Apa, Aquidaban o el Ypané? Un nuevo cauce se ubica por debajo de Asunción: podría tratarse del río Tebicuarí. Por el oeste del río Paraguay, aparecen sus afluentes como el Pilcomayo y, más al sur, el Bermejo. En el caso de los afluentes del río Paraná se menciona el Iguazú (guazú), el Piquirí, el Paraná-pané y el Tiete-Añemby, definido con su vocablo guaraní Yambi. Es sobre el circuito fluvial descrito, donde se citan pueblos españoles o reducciones: Asunción, el pueblo real de Guairá (mencionado como Guaira + pueblo), y las dos reducciones franciscanas más antiguas: el Alto y Jejuy.

Decíamos que el contexto de producción de la ilustración se comprende entre 1580 y los primeros años del siglo XVII. La presencia del Alto, reducción franciscana fundada en ese año, nos ofrece el punto temporal de partida. Es cierto que agentes de la orden están presentes en la región desde la segunda mitad del siglo XVI,55 pero la mención a San Lorenzo de los Altos y Jejuí constituye el dato duro. Estas son los primeros asentamientos franciscanos dirigidos por Alonso de San Buenaventura y su discípulo fray Luis de Bolaños. ${ }^{56}$ Pero si el mapa es posterior a 1580 ¿por qué se omiten las numerosas reducciones que crea la orden en las últimas décadas del siglo XVI? ${ }^{57}$ Puede que los Altos se lo conciba como centro aglutinador; el punto de referencia seleccionado por los franciscanos para inscribir su lugar en la Gobernación de Paraguay y Río de La Plata. ${ }^{58}$ ¿Y la mención Guaira + pueblo? Apuntaría a la ciudad Real de Guairá fundada hacia 1557 y a la Villa Rica del Espíritu Santo en 1580. Los franciscanos visitan con bastante recurrencia las dos ciudades; incluso realizan la tarea evangelizadora hacia Paraguay y la selva del Brasil tomando como punto de escala y referencia la Ciudad Real y Villa Rica. Una de las

\footnotetext{
${ }^{55}$ Los franciscanos Bernardo de Armenta y Alonso Lebrón llegan a Asunción en 1542, en compañía del adelantado Alvar Núñez Cabeza de Vaca. En 1550 arriba otro contingente y en 1570 se encuentra en la ciudad fray Pedro Fernández de la Torre, el primero en ocupar la diócesis del Río de La Plata con sede en Asunción. DURÁN ESTRAGÓ, Margarita San José de Caazapá. Un modelo de reducción franciscana, Comisión Quinto Centenario Don Bosco, Asunción, 1992, p. 33.

${ }^{56}$ Bolaños es el que traduce al guaraní el catecismo limense de 1583. Será una de las principales herramientas de conversión en las reducciones jesuíticas y franciscanas de lo que hoy es Paraguay, Brasil y el norte de Argentina. GANDÍA, Enrique de Historia de la conquista del Río de La Plata y del Paraguay. Los gobiernos de don Pedro de Mendoza, Alvar Núñez y Domingo de Irala, 1535-1556, Librería García Santos, Buenos Aires, 1932, pp. 256-278; DURÁN ESTRAGÓ, Margarita San José..., cit., p. 43-46; DURÁN ESTRAGÓ, Margarita Presencia Franciscana en el Paraguay (1538-1824), Ediciones y Arte, Asunción, 2005.

${ }^{57}$ Mientras el Alto comienza a funcionar con estabilidad, los franciscanos parten hacia el norte y fundan Pitum (Ypané) y Gurambaré y, unos años más tarde, Tobatí (1583), Itá (1585) y Yaguarón (1587). Hacia el sur y más distantes de los Altos se fundan Caazapá (1607) y Yuty (1611); hacia el norte Guarambaré $(1580)$ y San Francisco de Atyra (1580). Durán Estragó, San José de Caazapá. DURÁN ESTRAGÓ, Margarita Presencia Franciscana..., cit., pp. 4-5.

${ }^{58}$ En los primeros momentos, los Altos logra concentrar más de 1300 indígenas y el propio Hernandarias ordena crear su primera iglesia cubierta.
} 
referencias más representativas es el fuerte de Gaboto, fundado en 1527. ${ }^{59}$ Hay que advertir que están ausentes las misiones jesuíticas que desde 1609 comienzan a surgir por la zona. Por su parte, Loyola realiza dos recorridos por el espacio: en 1598, alcanzando asentamientos indígenas que están al borde del río Tieté y en 1604, cuando parte desde Buenos Aires para navegar ríos que bordean las reducciones franciscanas. ${ }^{60} \mathrm{El}$ mapa podría ser un producto de ambos viajes.

Si partimos que el boceto comunica al rey o al Consejo de Indias las primeras reducciones de los guaraníes, la autoría parece reducirse a los pocos franciscanos que se encuentran entre 1580 y 1604 por la Gobernación. Hasta los primeros años del siglo XVII no pasan de seis franciscanos los que se dedican al trabajo en las reducciones: entre los obispos están Hernando de Trejo y Sanabria que llega a Asunción en 1598 y Martín Ignacio de Loyola presente desde 1596 y como obispo desde 1603. Se suman a la lista los misioneros de la orden, que desde 1575 residen y dan vida a las reducciones: Alonso de San Buenaventura, Luis Bolaños y sus alumnos originarios del Paraguay: Gabriel de la Anunciación y Juan Bernardo. Todos ellos, juntos o separados, recorren la selva y los centros urbanos de la zona, llegando el río Tieté. A excepción de los últimos dos, Buenaventura, Bolaños, Loyola y Hernando de Trejo experimentan viajes transoceánicos. Eso sí, sólo Loyola conoce como pocos todos los rincones y continentes que aparecen en el boceto.

¿El mapa formaría parte de los expedientes que lo acompañan en su viaje hacia España en calidad de procurador de Buenos Aires? Puede que la ilustración haya sido considerada por las altas esferas políticas al momento de emitir la famosa Real Cédula de 1602, autorizando el comercio por Buenos Aires con Brasil y Guinea. No resultaría casual que esos tres espacios sean foco de atención en la ilustración. Si en todo caso Loyola o el resto de los franciscanos no son los responsables del mapa ¿será su amigo y gobernador Hernandarias, quien se esfuerza por "blanquear" el tráfico de Buenos Aires con Brasil? Hernandarias apoya el sistema de reducciones franciscanas desde su creación y realiza viajes por la zona antes y durante su mandato como gobernador. Hernandarias es amigo de Loyola, pero su red político-militar se

\footnotetext{
${ }^{59}$ El fuerte lo funda Sebastián Gaboto con el nombre de Sancti Spiritu. Es el primer asentamiento español en la región portuaria. Se encuentra a orillas del río Coronda, en la desembocadura del Carcarañá, a $50 \mathrm{~km}$. de la actual ciudad de Rosario, provincia de Santa Fe.

${ }^{60}$ El 12 de febrero de 1603 Hernandarias comunica al rey los planes que tiene junto al obispo: "nos partiremos el reverendísimo y yo con el divino favor a visitar toda la provincia que, a causa del poco tiempo que han durado en ella los obispos y gobernadores, se ha dado tan poco acierto en las cosas de importancia, que hay notable necesidad de reformación, así en lo eclesiástico como en lo secular, y principalmente en la reducción de los naturales". Citado en TELLECHEA, Ignacio Martín Ignacio..., cit., p. 75. Al año siguiente, Loyola le escribe al rey que visitó "las ciudades de Santa Fe, Concepción, Río Bermejo y las corrientes". MOLINA, Raúl Martín Ignacio..., cit., p. 52.
} 
extiende hacia el resto de los franciscanos: es hermano de Hernando de Trejo con quien viaja en 1598 hacia Asunción para una gira pastoral. Llega a ser el principal aliado de Bolaños cuando visita el Alto, alcanzado su máxima confianza cuando Hernandarias declara obligatoria las reducciones. Las múltiples redes entre Loyola, Hernandarias y demás franciscanos sugieren la posibilidad de una ilustración colectiva, pero con firma individual.

Fuera del foco concentrado entre los ríos Paraná y Paraguay aparecen otras referencias que apuntan a poblaciones indígenas. ¿El término muchas naciones se refiere a la parcialidad étnica de los Calchaquíes y Diaguitas? La mención genérica de guaranís ¿apuntaría a poblaciones indígenas que aún no se encuentran reducidas? Es posible, más sabiendo que la presencia jesuita toma peso en la primera década del siglo XVII, con su primera fundación en 1609: San Ignacio Guazú. ${ }^{61}$ Las misiones jesuíticas adoptan como antecedente inmediato el sistema de reducción franciscano.

Hacia el norte de ellas, se ilustra al río Amazonas, hasta alcanzar Chuquisaca, actual ciudad de Sucre (Bolivia), cercana al Cerro Rico de Potosí (155 km de distancia). Aquí el autor comete un error común de la época confundiendo el río Grande con el río Marañón. Si bien no confirma, el mapa deja entrever que ambos ríos terminan uniéndose con el delta mesopotámico en su desembocadura al Río de la Plata. En verdad, el río Marañón nace en el actual Perú y, al unirse con el Ucayali, forma el Amazonas. Por su parte, el Río Grande surge muy próximo a la actual capital boliviana y es un subafluente del Madeira. ${ }^{62}$ Al margen de la confusión geográfica, la ilustración denota el contacto directo entre las costas de Brasil con Potosí por el curso del río Amazonas y sin la mediación del Río de la Plata. ¿El autor piensa en el movimiento comercial portugués, intercambiando productos europeos por la plata? Si es así, el planteo remite a Loyola que, en una de sus cartas, dice que si Buenos Aires continúa sufriendo clausuras a su comercio, "el trato de Brasil a Potosí y de Potosí al Brasil" tomará mayores dimensiones de lo que hoy se vive. ${ }^{63}$

En primera escena aparece en el mapa un detallado listado de los puertos o costas luso-brasileras y, por el otro lado del Atlántico, los enclaves del norte africano y de la costa de Guinea. En cuanto al primer punto, se mencionan el "Cabo de S. Ag." (Cabo de Santo Agostinho), "Bahía de los Rei" (Salvador de Bahía), "ysleos" (Ilhéus), "Puerto Seguro" (Porto Seguro), “Espíritu Santo",

\footnotetext{
${ }^{61}$ FURLONG, Guillermo Misiones y sus pueblos guaraníes, Buenos Aires, 1962, pp. 92-93.

${ }^{62}$ En idéntico error tropieza el padre Diego de Ocaña (1599-1606) en su viaje desde España hacia Potosí en las mismas fechas que lo hace Loyola. OCAÑA, Diego de Un viaje fascinante por la América hispana del siglo XVI, ed. por Arturo Álvarez, Studium, Madrid, 1969, p. 213.

${ }^{63}$ Carta de Martín Ignacio de Loyola, obispo del Rio de la Plata, al presidente del Consejo de Indias, adjuntándole memorial sobre Filipinas en Documentos sobre el comercio de Filipinas, 1602, AGI, Filipinas, 35, N. 47, fol. 823-825.
} 
“San Sebastián" (São Sebastião), "San Vicente" (São Vicente), "Iguape", "San Francisco", "Ita ¿?" Itapoá, "Itayay" (Itajaí), "Santa Catarina” y Río Grande. En lo que sería el actual territorio de Uruguay: Río San Salvador, San Gabriel, Santa Bárbara, "islas de los Castillos" e "islas de los Lobos". Sobre el norte de África y costa de Guinea: Tripol (Trípoli), Túnez, Bugía, Argel, Oran, Argin (Arguin), Cabo Verde, y otros parajes de la costa occidental africana que no logramos dilucidar.

La Gobernación de Paraguay y Río de La Plata, costas de Brasil y de Guinea representan el marco espacial donde el autor inscribe el fenómeno que desea estudiar o comunicar al rey. ¿Apunta al comercio de esclavos? Es posible, teniendo en cuenta que los puntos costeros de Brasil constituyen escalas para el ingreso de la mano de obra africana hacia el Río de la Plata. Las rutas de navegación y comercio que se demarcan en la ilustración sugieren que todo contacto con y desde África debe tener su centro en Sevilla. No está considerado un tráfico de esclavos directo entre África y Brasil o Buenos Aires, sin pasar por el puerto hispano. Es posible sea una propuesta en defensa de los intereses de comerciantes españoles para el comercio de esclavos con Brasil y Buenos Aires. Ya hemos comentado la reiterada mención de estos espacios en las reflexiones de Loyola, en especial en su propuesta de 1602 de oficializar el movimiento de esclavos y la plata. Buenos Aires, Brasil y Guinea forman parte de una misma espacialidad y un único sistema comercial; coincidencia notable entre el mapa y Loyola.

Aparece España (Europa) y su enlace trasatlántico con Nombre de Dios, Panamá. Es un segundo nivel de atención en la ilustración. De la Península Ibérica se mencionan solo a La Coruña y Sevilla. Del resto de Europa a Francia, Marsella, Inglaterra, Italia y la ciudad papal: Roma. No aparece Madrid y tampoco Lisboa ni Portugal, sabiendo que muchas de las rutas transoceánicas que se trazan en el mapa son iniciativas o cuentan con la participación de los portugueses. El radio de acción del galeón de Portobelo aparece en un cuadro cerrado, circunscrito al área central del Atlántico, que se la define como "Mar de España", frontera en la que se ciñe el dominio español. ${ }^{64}$ Las islas y costas que forman parte del área de gravitación hispana son, desde el frente europeo, Sevilla, islas Canarias, islas Azores e islas de Madeira; desde el lado americano, islas españolas, Cuba, Bahamas, bordeando Jamaica hasta llegar a Portobelo.

A pesar que la referencia "Mar de España" tiene límites precisos, los flujos por el Atlántico se bifurcan hacia otros rincones que van más allá del navío oficial. El autor del mapa dibuja 4 derrotas adicionales hacia el Atlántico

\footnotetext{
${ }^{64}$ Véase la sugerente interpretación de Vives Anzacot sobre el relativo dominio hispano por el Atlántico. VIVES ANZACOT, Pedro "El Pacífico español: Frontera imperial, frontera americana," en GANCI, Massimo y ROMANO, Ruggiero (coords.) Gobernare il mondo. L'imperio spagnolo dal XV al XIX secolo, 1991, pp. 245-257.
} 
sur, siendo Sevilla el punto de salida: derrota al Campo y al Paraguay, al Río de La Plata, al Estrecho (de Magallanes) y, por último, de España a la India. Son vías de navegación en operación o proyectivas de carácter exploratoria, religiosa o comerciales. Sorprende el concepto campo para referirse al primer derrotero. ¿Apunta a un espacio alejado de la concentración urbana, distante de un pueblo?; ¿es un intento por demarcar una zona de frontera con los grupos indígenas no conversos, como tierra no conquistada por el español? ¿Tendría un significado ligado a la selva? Lejos estamos de pensar el término como área de cultivo o de sembradío.

Antes de ingresar "al Campo y al Paraguay", la ruta de Sevilla toca la isla de San Catalina y el puerto brasileño de San Francisco. El circuito remite al viaje del adelantado Alvar Núñez Cabeza de Vaca. Entre los años 1540 y 1541 navega desde Cádiz hasta la isla de Santa Catalina al mando de 3 naves con 400 personas y numerosos caballos. No todos llegaron con vida. Con la tripulación diezmada, Alvar Núñez atraviesa la selva y se encauza desde río arriba del Paraguay hasta alcanzar Asunción. Con fuertes conflictos con el antecesor Domingo Martínez de Irala logra tomar el cargo de Gobernador. ${ }^{65} \mathrm{El}$ autor de la ilustración podría dibujar el viaje del adelantado para referirse a los primeros franciscanos que lo acompañaron en la navegación: los citados Bernardo de Armenta y Alonso Lebrón. Es posible que estemos ante la intención del autor por comunicar al rey sobre uno de los caminos emprendido por los religiosos para llegar a las reducciones. No sabemos si Loyola, cuando viaja a España en 1601 para defender los intereses económicos de Buenos Aires realiza el trayecto por Perú-Panamá, por Buenos Aires o por el de Brasil.

La ruta hacia el Río de la Plata, se interna río arriba por el Río del Paraná. Puede que el autor advierta sobre el paso de Buenos Aires para llegar a las tempranas reducciones de los franciscanos. Pero también recuerda las frecuentes licencias concedidas por la Casa de Contratación de Sevilla para el comercio directo de navíos particulares con el puerto. El mapa cuenta en la parte superior con un extenso párrafo dedicado a las características geográficas y corrientes marítimas de la navegación entre España y el Río de la Plata. Es esta una de las principales comunicaciones que el autor intenta ofrecer a la Corona. ${ }^{66}$ Allí se menciona el frustrado viaje de Jaime Rasquín desde España

\footnotetext{
${ }^{65}$ GANDÍA, Enrique Historia ..., cit., pp. 95-105.

${ }^{66}$ Comunicamos aquí parte del texto legible: “Es [...] la navegación de [...] España al Rio Plata desde [...] febrero [...] mediado agosto o por septiembre [...] Y venía a cabo yo de y allegarse a la costa de África y Guinea al pasar de la línea equinoccial [sic] porque ay muchas calmas no yendo [...] junto a la costa y decaen las naos estuario [...] que calma en el pasaje de la línea a la ensenada del cabo de San Agustín el cual no pueden doblar y así les era forzado arribar a santo domingo y de allí a España como hizo Jaime Rasquín [sic]. Pasada la línea han de ir por la derrota por do le va a India y no vera es a la costa del Brasil porque era más arriba y en la ida que [...] teniendo el navío necesidad de agua o de otra cosa antes han de reconocer el estrecho y
} 
hacia el Río de La Plata, que llega como conquistador al Río de La Plata hacia mediados del siglo XVI. Amasa grandes fortunas y retorna a España en unas naves que le brinda su amigo, el obispo franciscano Pedro Fernández de la Torre. ${ }^{67}$ Realiza en España unas Relaciones sobre la situación de la Gobernación de Asunción y Río de la Plata que lo ameritan, a finales de 1558, su nombramiento como gobernador para suceder al fallecido Domingo de Irala. El mapa se refiere al desafortunado viaje realizado Rasquín en marzo de 1559, cuando la expedición que lo lleva a coronarse como gobernador carece de agua y alimentos, obligando a detener la marcha en la Antillas. ${ }^{68}$ No logrará tomar su cargo ni regresar al Paraguay.

Los restantes derroteros contienen un perfil más proyectivo: la del estrecho de Magallanes y la de la India, bordeando el Cabo de Hornos. ${ }^{69}$ El dominio hispano de la zona austral está cuestionado en ese tiempo por la presencia de piratas ingleses y holandeses, como las comandadas por Francis Drake (1578), Thomas Cavendish (1587) y la del holandés Olivier Van Noort (1601). ${ }^{70}$ La mención "derrota de España a la India" parece situarse como propuesta española como alternativa al circuito portugués por el cabo africano de Buena Esperanza rumbo a la India. Reconocemos una relación entre las derrotas desde Sevilla hacia el Pacífico sudamericano y el Oriente con las objeciones de Loyola. Su cuestionamiento a los grandes comerciantes de las Indias obedece no solo a una defensa del comercio por Buenos Aires, sino también a la desprotección que sufren los puertos del mar del Sur de Chile y del

de allí que voraz [...] el rio de la plata como aquí va figurado. A la vuelta de España saliendo por abril o mayo o junio que corre sur [...] van en cuarenta días a España que golpeados o su tomar otra ruta hasta Par.... [...] o hay [...] quieren pueden reconocer [...] a canarias o a las terceras".

${ }^{67}$ Pedro de la Torre funda la primera Catedral de Asunción. Había ingresado al Paraguay en 1555 y lo sucede en 1573 su colega franciscano, fray Juan del Campo. MORA MÉRIDA, José, Historia Social del Paraguay, 1600-1650, Escuela de Estudios Hispanoamericanos de Sevilla, Sevilla, 1973, pp. 665-87.

${ }^{68}$ La expedición está compuesta de tres naos: Jonás, San Juan y Trinidad con 650 tripulantes. FERNÁNDEZ DURO, Cesáreo Armada española. Desde la unión de los reinos de Castilla y Aragón, Museo Naval, Madrid, 1972, tomo II, pp. 197-199; GANDÍA, Enrique Historia ..., cit., pp. 298310.

${ }^{69}$ ¿Cuál es la razón de la distinción? ¿La ruta del Estrecho busca conectar Sevilla con el Pacífico hispanoamericano y la derrota por el Cabo de Hornos es la ilusión española de llegar a las especias de la India portuguesa? Recordemos que las expediciones cartográficas poco se detienen a particularizar las diferencias entre ambos pasos que conectan al Atlántico con el Pacífico.

${ }^{70}$ Luego de las expediciones de Magallanes (1520) y García de Loaisa (1526) por el Cabo austral, desde España se esfuerzan por conocer y controlar el paso sin mucho éxito. Para mayor detalle, BERNABÉU, Salvador El Pacífico Ilustrado: Del Lago Español a las Grandes Expediciones, Mapfre, Madrid, 1992, pp. 49-56 
mismo Perú de la orientación hacia Panamá. De ahí su visto bueno al trayecto del Cabo de Hornos como antesala para llegar al Pacífico. ${ }^{71}$

La resistencia de Loyola al poder concentrado de Lima termina por coincidir con la nimia referencia en la ilustración al eje Lima-Potosí-Buenos Aires. ${ }^{72}$ La capital del virreinato no se menciona, tampoco Potosí, ni Córdoba. Sí muestra la unión entre el fuerte de "Gaboto + Quito". En el medio del derrotero se encuentra Chuquisaca que dista de Gaboto a 250 (¿leguas?), pasando por Salta, Tucumán y Santiago del Estero. Allí mismo, cerca del fuerte de Gaboto, la orden franciscana establece una reducción de los Calchaquíes. El resto de las menciones por el área costera y marítima del Pacífico meridional son: Quito, el puerto de Paita, Perú, La Paz, Chile, Santiago y el puerto de Copiapó. Es evidente que el autor de la ilustración pretende revalorizar la inscripción de la región del Río de La Plata en el mundo atlántico.

En suma, es evidente que el rescate realizado en este ensayo del pensamiento y acción del Martín Ignacio de Loyola no obedece simplemente en una reseña biográfica de un agente franciscano. Estamos ante un caso ilustrativo de la notable movilidad de agentes a escalas macro-espaciales, de personas que le inyectaron verdadera dinámica y sentido a la temprana globalización. Sus derroteros planetarios le permitieron analizar un caso microregional, como la Gobernación de Asunción y Río de La Plata, en perspectiva global. Su mirada sobre la Gobernación articulando fenómenos que ocurren por el Atlántico como por el Pacífico es, en última instancia, un reconocimiento al carácter bipolar de la temprana globalización: la tensión de la América española entre el polo occidental-europeo y el polo asiático. Es así que Martín de Loyola decanta un estudio sobre Buenos Aires en su proyección atlántica pero también considerando las limitaciones y perjuicios de su inclinación hacia el eje del Pacífico con centralidad en Lima.

En segundo lugar y si alguna originalidad le cabe al ensayo, es la de dar a conocer un desconocido mapa de la gobernación de Asunción y Río de La Plata. No hemos podido concluir si el boceto le pertenece Martín Ignacio de Loyola, en calidad de autor individual o grupal. Pero los elementos comunes son notables. Al menos, la ilustración al menos circula por su inmediato entorno político y religioso. Por otro lado, el amplio encuadre espacial, temático y

\footnotetext{
${ }^{71}$ Cartas y expedientes de los obispos y arzobispos de Charcas, AGI, Charcas, 135, fol. 1-4.

72 En un principio pensamos en la posible autoría del mapa por parte del obispo de Tucumán, Fray de Victoria. En las últimas dos décadas del siglo XVI, cuando es mercader en el Perú, Victoria organiza dos expediciones comerciales hacia Brasil llevando plata a cambio de esclavos y productos europeos. El obispo tiene un gran conocimiento del camino Potosí-Buenos Aires, pasando por Tucumán y Córdoba. LEVILLIER, Roberto (ed.) Gobernación del Tucumán. Papeles de gobernadores en el siglo XVI, documentos del Archivo de Indias, Impr. de Juan Pueyo, Madrid, tomo I, 1920, p. 195. Desechamos esta posibilidad al notar que el boceto minimiza el eje Buenos AiresPotosí, magnificando la ruta fluvial Buenos Aires-Asunción, una región que Victoria no estudia.
} 
geopolítico en el que se ilustran las reducciones y gran parte de la gobernación nos acerca a su pensamiento y acción; es decir, a un actor ubicado en el puerto del Río de La Plata participando en la globalización temprana.

Ciudad de México, 30 de noviembre de 2018 